Open J. Math. Sci., Vol. 1(2017), No. 1, pp. 126 - 131

Website: https://pisrt.org/psr-press/journals/oms/

ISSN: 2523-0212 (Online) 2616-4906 (Print)

http://dx.doi.org/10.30538/oms2017.0012

\title{
COMPUTING SANSKRUTI INDEX OF TITANIA NANOTUBES
}

\author{
MUHAMMAD SHOAIB SARDAR, XIANG-FENG PAN, WEI GAO, \\ MOHAMMAD REZA FARAHANI ${ }^{1}$
}

\begin{abstract}
Let $G=(V ; E)$ be a simple connected graph. The Sanskruti index was introduced by Hosamani and defined as $S(G)=\sum_{u v \in E(G)}$ $\left(\frac{S_{u} S_{v}}{S_{u}+S_{v}-2}\right)^{3}$ where $S_{u}$ is the summation of degrees of all neighbors of vertex $u$ in $G$. In this paper, we give explicit formulas for the Sanskruti index of an infinite class of Titania nanotubes $\mathrm{TiO}_{2}[m, n]$.
\end{abstract}

AMS Mathematics Subject Classification: 05C12, 05C90.

Key words and phrases: topological index; molecular graph; Sanskruti index; Titania nanotube.

\section{Introduction}

Let $G=(V ; E)$ be a simple connected graph. In chemical graph theory, the sets of vertices and edges of $G$ are denoted by $V=V(G)$ and $E=E(G)$, respectively. A molecular graph is a simple finite graph such that its vertices correspond to the atoms and the edges to the bonds. A general reference for the notation in graph theory is $[1,2,3]$.

In chemical graph theory, we have many different topological index of arbitrary molecular graph $G$. A topological index of a graph is a number related to a graph which is invariant under graph automorphisms. Obviously, every topological index defines a counting polynomial and vice versa.

A graph can be recognized by a numeric number, a polynomial, a sequence of numbers or a matrix which represents the whole graph, and these representations

Received 02 August 2017. Revised 04 December 2017.

${ }^{1}$ Corresponding Author

(C) 2017 Muhammad Shoaib Sardar, Xiang-Feng Pan, Wei Gao, Mohammad Reza Farahani. This is an open access article distributed under the Creative Commons Attribution License, which permits unrestricted use, distribution, and reproduction in any medium, provided the original work is properly cited. 
are aimed to be uniquely defined for that graph. A topological index is a numeric quantity associated with a graph which characterizes the topology of the graph and is invariant under graph automorphism. There are some major classes of topological indices such as distance based topological indices, degree based topological indices and counting related polynomials and indices of graphs. Among these classes degree based topological indices are of great importance and play a vital role in chemical graph theory and particularly in chemistry.

Among topological descriptors, connectivity indices are very important and they have a prominent role in chemistry. One of the best known and widely used is the connectivity index $R(G)=\sum_{u v \in E(G)} \frac{1}{\sqrt{d_{u} d_{v}}}$ introduced in 1975 by Milan Randić (see [4]), who has shown this index to reflect molecular branching. The Sanskruti index $S(G)$ of a graph $G$ is defined as follows (see [5]):

$$
S(G)=\sum_{u v \in E(G)}\left(\frac{S_{u} S_{v}}{S_{u}+S_{v}-2}\right)^{3} .
$$

where $S_{u}$ is the summation of degrees of all neighbors of vertex $u$ in $G$. In this paper, we compute the Sanskruti index for an infinite class of Titania nanotubes. For more details about Sanskruti index we refer to the articles $[6,7,8,9,10,11]$.
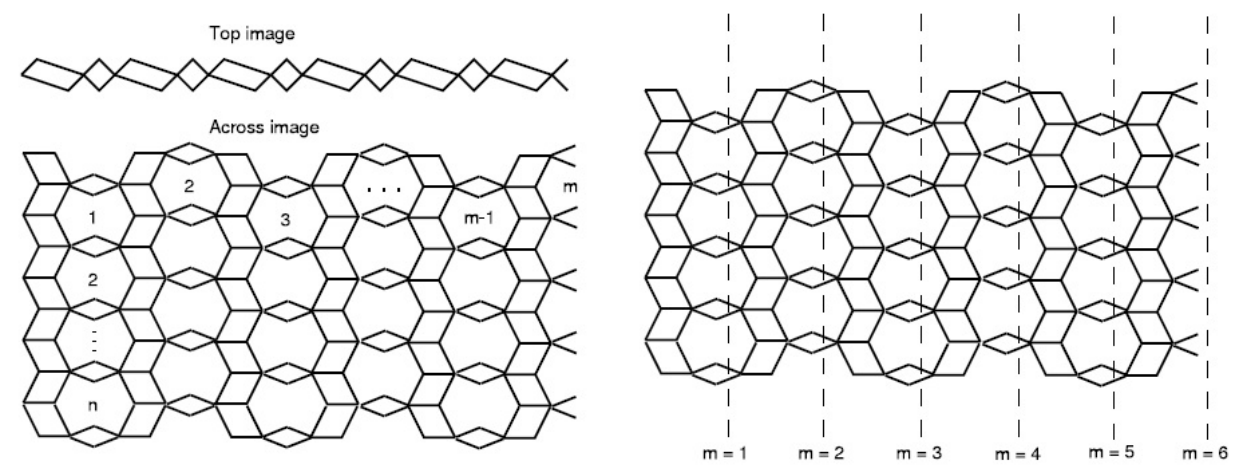

Figure 1. The graph of $\mathrm{TiO}_{2}[m, n]-$ nanotubes, for $m=6$ and $n=4$.

\section{Main results and discussion}

As a well-known semiconductor with numerous technological applications, Titania is comprehensively studied in materials science. Titania nanotubes were systematically synthesized during the last 10-15 years using different methods and carefully studied as prospective technological materials. Since the growth mechanism for $\mathrm{TiO}_{2}$ nanotubes is still not well defined, their comprehensive theoretical studies attract enhanced attention. $\mathrm{TiO}_{2}$ sheets with a thickness of a 
few atomic layers were found to be remarkably stable [12]. Recently Malik and Imran [13] and some others researchers computed multiple Zagreb index of $\mathrm{TiO}_{2}$ nanotubes, readers can see the paper series $[14,15,16,17,18,19,20,21,22,23$, $24,25,26,27]$.

The graph of the Titania nanotube $\mathrm{TiO}_{2}[m, n]$ is presented in Fig. 1 where $m$ denotes the number of octagons in a row and $n$ denotes the number of octagons in a column of the Titania nanotube.

Let us define the partitions for the vertex set and the edge set of the Titania nanotube $\mathrm{TiO}_{2}$, for $\delta(G) \leq k \leq \Delta(G), 2 \delta(G) \leq i \leq 2 \Delta(G)$, and $\delta(G)^{2} \leq j \leq \Delta(G)^{2}$, then we have [28]

$$
\begin{gathered}
V_{k}=\{v \in V(G) \mid \operatorname{deg}(v)=k\}, \\
E_{i}=\{e=u v \in E(G) \mid d(u)+d(v)=i\} .
\end{gathered}
$$

In the molecular graph of $\mathrm{TiO}_{2}$-nanotube, we can see that $2 \leq d(G) \leq 5$. So, we have the vertex partitions as follows.

$V_{2}=\{u \in V(G) \mid d(u)=2\}, V_{3}=\{u \in V(G) \mid d(u)=3\}$.

$V_{4}=\{u \in V(G) \mid d(u)=4\}, V_{5}=\{u \in V(G) \mid d(u)=5\}$.

It is easy to see that $\left|V_{2}\right|=2 m n+4 n,\left|V_{3}\right|=2 m n,\left|V_{4}\right|=2 n,\left|V_{5}\right|=2 m n$, So we have $\left|V\left(\mathrm{TiO}_{2}\right)\right|=6 n(m+1)$. Similarly, the edge partitions of the graph $\mathrm{TiO}_{2}$ are as follows.

$E_{6}=\{e=u v \in E(G) \mid d(u)=2$ and $d(v)=4\}$.

$E_{7}=\{e=u v \in E(G) \mid d(u)=2$ and $d(v)=5\}$

$\cup\{e=u v \in E(G) \mid d(u)=3$ and $d(v)=4\}$.

$E_{8}=\{e=u v \in E(G) \mid d(u)=3$ and $d(v)=5\}$.

The vertex partition $V_{k}$ and the edge partitions $E_{i}$ are collectively exhaustive, that is

$$
\bigcup_{k=\delta(G)}^{\Delta(G)} V_{k}=V(G), \bigcup_{i=2 \delta(G)}^{2 \Delta(G)-2} E_{i}=E(G)
$$

\begin{tabular}{cccc}
\hline Edge partition & $E_{6}$ & $E_{7}$ & $E_{8}$ \\
\hline Cardinality & $6 n$ & $4 m n+4 n$ & $6 m n-2 n$
\end{tabular}

Table 1:The edge partitions based on degrees of end vertices

\begin{tabular}{ccccccc}
\hline$\left(S_{u}, S_{v}\right)$ where $u v \in E\left(\mathrm{TiO}_{2}[\mathrm{~m}, n]\right)$ & $(10,5)$ & $(7,5)$ & $(7,9)$ & $(8,9)$ & $(10,9)$ & $(11,9)$ \\
\hline Numbers of edges & 2 & 2 & $2 n$ & $4 n$ & $2 n$ & $6 m$ \\
\hline
\end{tabular}

Table 2:The edge partitions based on degree sum of neighbors of end vertices

\begin{tabular}{cccccc}
\hline$\left(S_{u}, S_{v}\right) \forall u v \in E\left(\mathrm{TiO}_{2}[\mathrm{~m}, n]\right)$ & $(13,9)$ & $(7,13)$ & $(10,13)$ & $(11,13)$ & $(13,13)$ \\
\hline Numbers of edges & $3 m$ & $2 n$ & $4 m n+2 n$ & $2 m n-2 n$ & $6 m n-4 n$ \\
\hline
\end{tabular}

Table 3:The edge partitions based on degree sum of neighbors of end vertices 
Theorem 2.1. The Sanskruti index $S(G)$ of Titania nanotube $G=\mathrm{TiO}_{2}[\mathrm{~m}, n]$ is given by

$S(G)=\frac{1753571}{8788}-\frac{5732099098294657}{19655694576000} n+\frac{12790839}{8000} m+\frac{8788000}{9261} m n+\frac{6092281}{2304} m n$.

Proof. To compute the Sanskruti index $S(G)$ of Titania nanotube $\mathrm{TiO}_{2}[m, n]$, we need an edge partition of the Titania nanotube $\mathrm{TiO}_{2}[m, n]$, based on degree sum of neighbors of end vertices of each edge. We presented these partitions with their cardinalities in Tables 2 and 3. Now using Eq. (1) and Tables 2 and 3 we get the required result as follows.

$S\left(\mathrm{TiO}_{2}[\mathrm{~m}, n]\right)=\sum_{u v \in E(G)}\left(\frac{S_{u} S_{v}}{S_{u}+S_{v}-2}\right)^{3}=2\left(\frac{10 \times 5}{10+5-2}\right)^{3}+2\left(\frac{7 \times 5}{7+5-2}\right)^{3}+2 n\left(\frac{7 \times 9}{7+9-2}\right)^{3}+$ $4 n\left(\frac{8 \times 9}{8+9-2}\right)^{3}+2 n\left(\frac{10 \times 9}{10+9-2}\right)^{3}+6 m\left(\frac{11 \times 9}{11+9-2}\right)^{3}+3 m\left(\frac{13 \times 9}{13+9-2}\right)^{3}+2 n\left(\frac{7 \times 13}{7+13-2}\right)^{3}+(4 m n+$ $2 n)\left(\frac{10 \times 13}{10+13-2}\right)^{3}+(2 m n-2 n)\left(\frac{10 \times 5}{10+5-2}\right)^{3}+2\left(\frac{10 \times 5}{10+5-2}\right)^{3}=\frac{1753571}{8788}-\frac{5732099098294657}{19655694576000} n+$ $\frac{12790839}{8000} m+\frac{8788000}{9261} m n+\frac{609281}{2304} m n$.

The proof of theorem is completed.

\section{Competing Interests}

The author(s) do not have any competing interests in the manuscript.

\section{REFERENCES}

1. West, D.B. (1996). An Introduction to Graph Theory. Prentice-Hall.

2. Trinajstic, N. (1992). Chemical Graph Theory. CRC Press, Bo ca Raton, FL.

3. Todeschini, R., Consonni, V. (2000). Handbook of Molecular Descriptors. Wiley, Weinheim. .

4. Randić, M. (1975). Characterization of molecular branching. Journal of the American Chemical Society, 97(23), 6609-6615.

5. Hosamani, S. M. (2017). Computing Sanskruti index of certain nanostructures. Journal of Applied Mathematics and Computing, 54(1-2), 425-433.

6. Gao, Y. Y., Sardar, M. S., Hosamani, S. M., \& Farahani, M. R. (2017). Computing sanskruti index of TURC4C8 (s) nanotube. International Journal of Pharmaceutical Sciences and Research, 8(10), 4423-4425.

7. Jiang, H., Sardar, M. S., Farahani, M. R., Rezaei, M., \& Siddique, M. K. (2017). Computing sanskruti index of v-phenylenic nanotubes and nanotori. Internaional Journal of Pure and Applied Mathematics, 115(4) , 859-865.

8. Zhang, X., Sardar, M. S., Zahid, Z., Rezaei, M., \& Farahani, M.R. (2017). Computing sanskruti index of capra-designed planar benzenoid series $C a_{k}\left(C_{6}\right)$. Internaional Journal of Pure and Applied Mathematics, 115(4), 2017, 851-858.

9. Sardar, M. S., Zafar, S., \& Farahani, M. R. (2017). Computing Sanskruti index of the Polycyclic Aromatic Hydrocarbons. Geology, Ecology, and Landscapes, 1(1), 37-40.

10. Gao, Y., Sardar, M. S., S. Zafar, \& Farahani, M.R. (2017). Computing Sanskruti index of dendrimer nanostars. Internaional Journal of Pure and Applied Mathematics, 115(2), 399-404.

11. Gao, Y., Farahani, M. R., Sardar, M. S., \& Zafar, S. (2017). On the Sanskruti Index of Circumcoronene Series of Benzenoid. Applied Mathematics, 8(4), 520-524.

12. Evarestov, R. A., Zhukovskii, Y. F., Bandura, A. V., \& Piskunov, S. (2011). Symmetry and models of single-walled $\mathrm{TiO} 2$ nanotubes with rectangular morphology. Central European Journal of Physics, 9(2), 492-501. 
13. Malik, M. A., \& Imran, M. (2015). On multiple Zagreb index of TiO2 nanotubes. Acta Chimica Slovenica, 62(4), 973-976.

14. Farahani, M. R., Jamil, M. K., \& Imran, M. (2016). Vertex PIv topological index of Titania Nanotubes. Applied Mathematics and Nonlinear Sciences, 1(1), 170-176.

15. Farahani, M.R., Jamil, M.K., Pradeep Kumar,R., \& Rajesh Kanna, M.R. (2016). Computing Edge. Co-Padmakar-Ivan Index of Titania T iO2(m,n). Journal of Environmental Science, Computer Science and Engineering \& Technology. 5(3), 285-295.

16. Farahani, M. R., Kumar, R. P., Kanna, M. R., \& Wang, S. (2016). The vertex szeged index of titania carbon nanotubes $\mathrm{TiO} 2(m, n)$. International Journal of Pharmaceutical Sciences and Research, 7(9), 3734-3741.

17. Gao, W., Jamil, M. K., Farahani, M. R., \& Imran, M. (2016). Certain Topological Indices of Titania Carbon Nanotubes $\mathrm{TiO} 2(\mathrm{~m}, \mathrm{n})$. Journal of Computational and Theoretical Nanoscience, 13(10), 7324-7328.

18. Gao, W., Farahani, M. R., \& Imran, M. (2017). About the Randić Connectivity, Modify Randić Connectivity and Sum-connectivity Indices of Titania Nanotubes TiO2 (m, n). Acta Chimica Slovenica, 64 (1), 256-260.

19. Gao, W., Farahani, M. R., Jamil, M. K., \& Siddiqui, M. K. (2016). The Redefined First, Second and Third Zagreb Indices of Titania Nanotubes TiO2 [m, n]. The Open Biotechnology Journal, 10(1) 272-277.

20. Huo, Y., Liu, J. B., Imran, M., Saeed, M., Farahani, M. R., Iqbal, M. A., \& Malik, M. A. (2016). On Some Degree-Based Topological Indices of Line Graphs of TiO2 $[m, n]$ Nanotubes. Journal of Computational and Theoretical Nanoscience, 13(12), 9131-9135.

21. Li, Y., Yan, L., Farahani, M. R., Imran, M., \& Jamil, M. K. (2017). Computing the Theta Polynomial $T(G, x)$ and the Theta Index $T(G)$ of Titania Nanotubes TiO2 (m, n). Journal of Computational and Theoretical Nanoscience, 14(1), 715-717.

22. Liu, J. B., Gao, W., Siddiqui, M. K., \& Farahani, M. R. (2016). Computing three topological indices for Titania nanotubes. AKCE International Journal of Graphs and Combinatorics, 13(3), 255-260. 2016.

23. Yan, L., Li, Y., Hayat, S., Siddiqui, H. M. A., Imran, M., Ahmad, S., \& Farahani, M. R. (2016). On Degree-Based and Frustration Related Topological Indices of Single-Walled Titania Nanotubes. Journal of Computational and Theoretical Nanoscience, 13(11), 90279032.

24. Yan, L., Li, Y., Farahani, M. R., \& Imran, M. (2016). Sadhana and Pi polynomials and their indices of an infinite class of the Titania Nanotubes TiO2 (m, n). Journal of Computational and Theoretical Nanoscience, 13(11), 8772-8775.

25. Yan, L., Li, Y., FARAHANI, M. R., \& JAMIL, M. K. (2016). The Edge-Szeged index of the Titania Nanotubes TiO2 (m, n). International Journal of Biology, Pharmacy and Allied Sciences. 5(6), 1260-1269.

26. Sardar, M. S., Zafar,S., \& Farhani, M. R. (2017). The generalized Zagreb index of capradesigned planar benzenoid series $C a_{k}\left(C_{6}\right)$. Open J. Math. Sci. 1(1), 44-51. 2017.

27. Rehman, H.M. Sardar, R. \& Raza, A. (2017). Computing topological indices of hex board and its line graph. Open J. Math. Sci. 1(1), 62-71.

28. Farahani, M. R. (2012). Some connectivity indices and Zagreb index of polyhex nanotubes. Acta Chim. Slov, 59, 779-783.

\section{Muhammad S. Sardar}

School of Mathematical Sciences, Anhui University, Hefei 230601, China.

e-mail: shoaibsardar093@gmail.com

Xiang-Feng Pan

School of Mathematical Sciences, Anhui University, Hefei 230601, China.

e-mail: xfpan@ahu.edu.cn 


\section{Wei Gao}

School of Information and Technology, Yunnan Normal University, Kunming, 650500, China.

e-mail: gaowei@ynnu.edu.cn

Mohammad R. Farahani

Department of Applied Mathematics, Iran University of Science and Technology(IUST), Narmak, Tehran 16844, Iran.

e-mail: Mrfarahani@mathdep.iust.ac.ir, Mrfarahani88@gmail.com 